\title{
Foreword: Issues and Creative Strategies in Archaeological Heritage Conservation, Education, and Management
}

\author{
Kathleen Tantuico ${ }^{1,3}$ and Kristine Kate \\ $\operatorname{Lim}^{2,3,4}$ \\ ${ }^{1}$ University of the Philippines-College of Law \\ ${ }^{2}$ Institute of Geographical Sciences, \\ Department of Earth Sciences, Freie Universität \\ ${ }^{3}$ Tuklas Pilipinas Society \\ ${ }^{4}$ Kapisanan ng mga Akeologist sa Pilipinas, Inc \\ Correspondence \\ kdtantuico@up.edu.ph
}

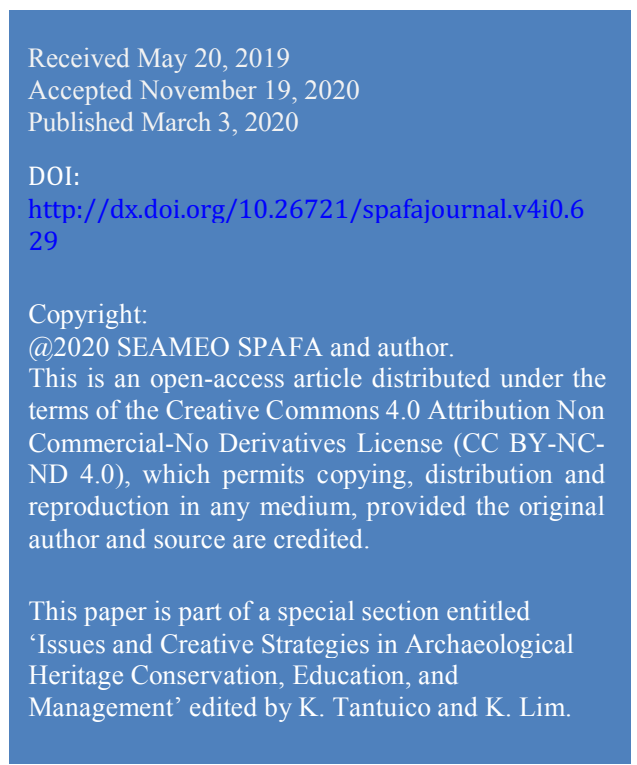

\begin{abstract}
This publication is a compilation of papers presented at the panel discussion of the same title at the 21st Congress of the Indo-Pacific Prehistoric Association at the Huong Giang Hotel in Hue, Vietnam on September 24, 2018. It is inspired by the Editors' advocacy of instilling archaeological awareness and heritage literacy to communities in which archaeological sites are situated.
\end{abstract}

Keywords:

heritage literacy, public archaeology, heritage management, cultural dissemination

\section{Rethinking strategies in heritage management and cultural dissemination}

The rapid development of research methodologies around the world has introduced new methods not just of archaeological excavation, but also novel approaches of disseminating archaeological information to interested parties. Recent studies in Egypt (Mosir et al. 2002), the United States of America (Atalay 2006), Thailand (Natapintu 2007) and the Philippines (Acabado et al. 2014) have presented a collaborative approach between the general public and archaeologists. This provides opportunities through which members of communities can partner with formally trained archaeologists in conducting archaeological excavations. The same examples show that when the local government uses archaeological knowledge to cultivate heritage-oriented community services and amenities, the people of the area feel more connected to their culture and past, empowering them to contribute more in society, to work harder, or to be better citizens of their respective countries.

These studies have shown that archaeological information and heritage can be effectively integrated into a variety of contexts if archaeologists and heritage practitioners go beyond the general description of outreach and public involvement and seek more relevant, proactive, and critical means of engagement (Jameson 2019). It has also been concluded that archaeologists must provide communities with opportunities whereby they can also own and benefit from the intellectual benefits reaped from archaeological excavations. 
The involvement of community members where archaeological sites are located not only in archaeological excavations, but also in ways by which information garnered from archaeological excavations are partially controlled, interpreted and disseminated is known as community archaeology, an emerging field of archaeology that aims for a holistic collaboration with these communities and archaeologists. With this new framework for the application and dissemination of archaeological knowledge that includes the "community" as stakeholders, it is now crucial for the re-examination and evaluation of existing practices of archaeological research and current frameworks in heritage management, tourism and cultural dissemination (Marshall 2002).

Challenges such as the lack of educational capacity, human resources and funding within the local government and communities should be an impetus to create effective ways for professionally trained archaeologists to connect with the general public and other fields. The need for heritage practitioners to increase their engagement with local communities and government agencies is crucial to arrive at relevant heritage management strategies. Additionally, there is also a need to assess and revitalize the implementation of heritage laws and/or national policies on culture and heritage.

This publication is a compilation of papers presented at the panel discussion of the same title at the 21 st Congress of the Indo-Pacific Prehistoric Association at the Huong Giang Hotel in Hue, Vietnam on September 24, 2018. It is inspired by the Editors' advocacy of instilling archaeological awareness and heritage literacy to communities in which archaeological sites are situated.

In 2015, the Editors, along with their colleagues who are all affiliated with the University of the Philippines- Archaeological Studies Program, formed Tuklas Pilipinas Society Inc., a NonGovernment Organization that formulates interactive educational activities and training workshops designed to engage school children, adults and heritage workers that instill archaeological awareness and heritage literacy, as articulated in this compilation's papers:

Ms. Natasha Kintanar and Dr. Grace Barretto-Tesoro introduce Tuklas Pilipinas Society, and demonstrates how creative interactive activities can incorporate results from archaeological excavations and be disseminated to the communities in which archaeological sites are located. In this paper, they share the methods used in conducting a workshop for the residents of San Juan, Batangas, Central Luzon, Philippines, where they themselves were involved in a series of archaeological excavations that uncovered Spanish-era ruins.

Ms. Charmaine Ledesma, a Program Officer at the Guam Preservation Trust and a participating archaeologist during excavations in Kiangan, Ifugao, Northern Luzon, Philippines in 2012 and 2013, shares data from a study conducted in Kiangan elementary schools that aimed to develop modules that include excavation results to supplement the current social studies curriculum for Fifth Graders.

Mr. Nguyen Huy Nham, a Ph.D. student at Kanazawa University, Japan, demonstrates that inadequate heritage laws and a lack of consultation among major stakeholders such as government institutions, industrial developers and local communities can contribute to the threat of destruction of the Vuon Chuoi Archaeological site in Hanoi, Vietnam. He also documents how local 
communities and media outlets can collaborate in the dissemination of cultural heritage information as a means of protecting the site.

The abstracts of the other presenters are also included at the end of this introduction. This collection of papers aims to be a platform whereby archaeologists and heritage workers can share their experiences and learnings from protecting, promoting, and managing archaeological heritage. These studies involve the inter-mingling concepts of legislation, law/policy implementation, urban/regional planning, education, tourism, environmental management, and communication. With these new pieces of information, new ways of communicating archaeological knowledge may lead to more effective heritage management and preservation strategies for a more sustainable and community-integrated cultural and archaeological education.

The editors would like to acknowledge the assistance of Dr. Stephen Acabado of the University of California- Los Angeles, Dr. Noel Hidalgo Tan and the members of the Tuklas Pilipinas Society in the production of this compilation.

Quezon City, Metro Manila, Philippines, March 2019

\section{References}

Acabado, S, Martin M and Lauer, AJ (2014) Rethinking History, Conserving Heritage: Archaeology and Community Engagement in Ifugao, Philippines. The SAA Archaeological Record 14(5): 12-17.

Atalay, S (2006) Indigenous Archaeology as Decolonizing Practice. American Indian Quarterly 30(3/4): 280-310.

Jameson, JH (2019) Introduction: The Critical Junctures of Archaeology, Heritage, and Communities. In: J Jameson and S Musteaţă (eds.) Transforming Heritage Practice in the 21st Century. Cham: Springer, 1-12.

Marshall, Y (2002) What Is Community Archaeology? World Archaeology 34(2): 211-219.

Natapintu, S (2007) Contribution of Archaeology to the Quality of Life Improvement at the Village of Ban Pong, Manao, Lopburi Province, Central Thailand. In Mokhtar Saidin and S. Chia (eds.) Proceedings of the International Seminar on Archaeology and National Building August 2005. Penang: Pusat Penyelidikan Arkeologi Malaysia, University Sains Malaysia, 22-31.

Mosir, S, Glazier, D, Philipps, JE, Nasser el Nemr, L, Mohammed Saleh Mousa, Aleshm RN, Richardson, S, Conner, A and Seymour, M (2002) Transforming archaeology through practice: Strategies for collaborative archaeology and the Community Archaeology Project at Quesir, Egypt. World Archaeology 34:2: 220-248.

\section{Other Abstracts}

Exploring the Invisible Past through the Visible Heritage: Lessons from Teaching the Archaeology of Manila through a Mobile Lecture

Timothy James Vitales

Founding member, Tuklas Pilipinas 
Teaching archaeology and prehistory in the city poses a great challenge, especially in the absence of visible archaeological sites to illustrate on. In the case of Manila, its early heritage prior to the Spanish colonization is not totally realized due to the overwhelming presence of Spanish colonial and modern structures. Such challenge was taken up by the non-government organization known as Tuklas Pilipinas whose aim is to provide heritage literacy to the Filipinos through archaeology, history, and anthropology, among others. One of its major services, the ArchaeoTrails gives us a glimpse of the early Manila through lectures in different heritage spaces. It is an interactive activity, which allowed the audience to experience the past, discover archaeological concepts, and challenge conventional notions about Philippine culture and heritage. This paper will discuss the development of the Manila ArchaeoTrails educational module and the lessons learned throughout the process.

Dealing with Living People and Dead People: Experiences from Archaeological Fieldwork in Pang Mapha, Mae Hong Son, Thailand

Wokanya Na Nongkhai

Researcher, Prehistoric Population and Cultural Dynamics in the Highland Pang Mapha Project, Thailand

Cultural management and community-based archaeology are very important for preserving cultural heritage. A new Log Coffin Cave in Long Long Rak, Mae Hong Son, Thailand, was discovered in 2010 and excavated in 2013 and 2016 under the Interactions between Human and their Environments in Highland Pang Mapha, Mae Hong Son Province Research Project (IHEP). Unprecedented archaeological evidence of Log Coffin culture was unearthed - in particular, in situ human remains and varieties of organic artefacts in log coffins. This provides new archaeological knowledge of death ritual, social status, and the early migration of ancient people - probably Taiduring the Iron Age, dating to 1000-2300 BP. Consequently, this has become a key site of Thailand for understanding Log Coffin culture and ancient hilltribes.

This raises the question of how to encourage the seven ethnic groups who live near the cave to recognize and manage their heritage, based on a concept of Cultural Pluralism. While conducting the project, there were complexities concerning working with communities. This paper thus aims to present and share research strategies and experiences. Participatory action research was the main method used. Many activities, including community forums, interviews, and observations, were organized. Recent research results indicate that: 1) local communities have agreed to draw up a future plan for managing Long Long Rak cave; 2) local schools are cooperating to write a local history curriculum, producing educational media, and developing this site; 3 ) the government will provide the budget and cooperate in creating a site management plan, while IHEP will provide archaeological knowledge; 4) mass media such as newspapers and television will help to broadcast the research results and promote the site.

Out of the Frying Pan \& into the Fire?: from 'Citizen Science' to Undergraduate Student Exchange in Southeast Asian Archaeology - how useful are these approaches for local communities?

Dr Nigel Chang

Department of Archaeology, School of Arts \& Social Sciences James Cook University Queensland, Australia

I have been involved with 'Citizen Science' in Thai Archaeology for over 20 years. In this process international volunteers work with the archaeology team (post-graduate students \& researchers) and alongside employed local participants. As well as their time, the volunteers make a financial 
contribution that helps, in particular, to pay the local team. More recently, the Australian Government has offered various schemes to fund bringing Australian undergraduates to Southeast Asia to build person-to-person networks and to promote culture \& language exchange: most recently, the New Colombo Plan. Our archaeological projects have increasingly involved these students, alongside local Thai and/or Lao university student peers.

In this presentation I compare the two approaches with particular reference to how they affect, and provide opportunities for, local involvement \& capacity building. I argue that these should be fundamental outcomes of archaeology. I discuss ongoing projects in Laos \& Thailand and consider local, regional, central government \& academic communities. And, finally, why 'Frying Pans' \& 'Fires'..? I will also discuss some of the 'challenges' of running archaeology projects involving such a broad range of participants.

The Aeschylus Museum: Using historical evidence and community engagement for modern catharsis

Madison Leeson

President, Aeschylus Museum, Greece; University of Kent in Eleusis, Greece

\section{Antonio Nuñez}

Director, Aeschylus Museum, Greece; University of Kent in Eleusis, Greece

Catharsis (from Greek кá $\theta \alpha \rho \sigma ı \varsigma$ meaning "purification" or "cleansing") is the purification and purgation of emotions - particularly pity and fear - through art or any extreme change in emotion that results in renewal and restoration. The Museum strives to bring about a modern catharsis through the arts, by making the life and work of the ancient Greek tragedian Aeschylus accessible and relevant to all. Through exhibitions, a collection of archives and artifacts, artistic and educational programming, and partnerships with the local, national, and international community, the Aeschylus Museum serves to renew the cultural centre of Eleusis and rekindle a general passion for appreciation of the arts.

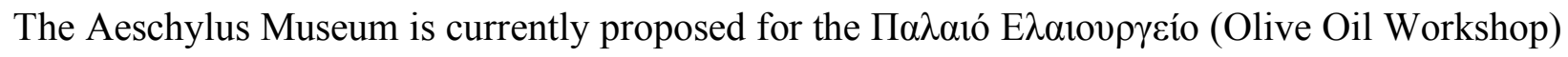
site on the coast of the Gulf of Elefsina; many scholars believe this to be the ancient site of the original theatre of Eleusis. The Museum will focus on a collections-free strategy of educating visitors through digital exhibitions and hands-on activities as well as performances of Aeschylus' works in the on-site open-air theatre. The Museum's purpose is to emphasize the historical evidence of the influence of Aeschylus and to encourage visitors to consider his works as they transcend time. Beyond merely presenting his works, the Museum will strive to stimulate discussion of the ideas within and throughout the experiences of the visitors. The exhibitions and performances will be bilingual.

The Museum's direction has been developed through extensive consultations with the local community, community organizations, and partnerships with the Foundation of the Hellenic World and the Heritage Management Organization. The Museum is currently in development, to be launched at a date not yet confirmed.

'Best Practice' Bridging: Addressing gaps in the law with community engagement Antoinette Hennessy, Kylie Lower, Quenten Agius 
Though offering some protection, heritage laws are often insufficient for appropriate management of cultural heritage. Fortunately, our obligations as heritage practitioners are not limited to the law, and extend to guidelines offered by codes of ethics; United Nations Conventions; and 'best practice' approaches. Indeed, in light of the limitations of legislation, can be a necessity to draw on these guidelines to properly manage and mitigate damage to cultural heritage, particularly as land becomes more intensively subjected to development.

In the case of Australia, areas that fall in the traditional lands of Indigenous Australians (many of whom have been displaced through colonization, but today seek to rectify damages through Native Title) are becoming increasingly pursued for large-scale, commercial projects such as mining and renewable energy pursuits. However, due to their remoteness and location on private properties, little to no archaeological, anthropological or ethnographic investigations have been conducted in these areas. While developments can heritage in put heritage at risk of harm, it also provides an opportunity for Indigenous communities to be involved in the consultation process, to reconnect with their heritage and to manage it on their terms.

We refer to a recent project in regional South Australia, in cooperation with the Ngadjuri community, to demonstrate the positive negotiation outcomes that benefit both community and developers in the long term. Though we draw from our experiences in South Australia, the approaches to 'best practice' consultation, cultural heritage management and community engagement can be applied to other countries in similar circumstances.

\section{Empowering Cultural Identities of Orang Asli Temiar through Cultural Mapping} Chaw Yeh Saw, Hsiao Mei Goh, Suhana Yusof, Noridayu Bakry and Deejay Daxter A. Albert Centre for Global Archaeological Research (CGAR), Universiti Sains Malaysia

Orang Asli (Indigenous) community in Malaysia has always been considerd as a marginalised group. The attributes of the Orang Asli villages remain unknown to the outer world because most of the activites are held internally inside the village or among Orang Asli villages only. Nowadays, even the younger generation of the Orang Asli in Kinta Valley of West Malaysia, do not show rmuch interest or knowledge regarding their own cultural heritage particularly on their very own cultural landscape due in part to the lack of basic mapping skills among the community. The absence of a detailed map regarding the villages' environment and cultural aspects also resulted in relatively low visiting experience for the visitors. In respond to the aforementioned issues, this project aims to assist the Orang Asli community to map out the boundaries, landscape features, attributes, distribution of household and concentration of cultural activities in the Orang Asli village, which all these data will be integrated into the development of a detailed map of the village. This project is of high significance because it is the very first collaborative project between the Orang Asli community and Universiti Sains Malaysia as a means to empower the cultural identities of the Orang Asli community. 